\title{
Maternal hydronephrosis in normal pregnancy in Bayelsa state, South-South Nigeria
}

\author{
Peter Chibuzor Oriji ${ }^{1}$, Enefia Kelvin Kiridi ${ }^{2,3 *}$, Isaac Joel Abasi ${ }^{4}$
}

\begin{abstract}
${ }^{1}$ Department of Obstetrics and Gynaecology, Federal Medical Centre, Yenagoa, Bayelsa State, Nigeria
${ }^{2}$ Department of Radiology, Niger Delta University Teaching Hospital, Okolobiri, Bayelsa State, Nigeria

${ }^{3}$ Silhouette Radiodiagnostic Consultants, Yenagoa, Bayelsa State, Nigeria

${ }^{4}$ Department of Obstetrics and Gynaecology, Niger Delta University Teaching Hospital, Okolobiri, Bayelsa State, Nigeria
\end{abstract}

Received: 02 February 2022

Accepted: 17 February 2022

\author{
*Correspondence: \\ Enefia Kelvin Kiridi, \\ E-mail: kiridienefia@gmail.com
}

Copyright: () the author(s), publisher and licensee Medip Academy. This is an open-access article distributed under the terms of the Creative Commons Attribution Non-Commercial License, which permits unrestricted non-commercial use, distribution, and reproduction in any medium, provided the original work is properly cited.

\begin{abstract}
Background: Hydronephrosis is a common finding in normal pregnancy. It is the dilatation of the renal calyces and pelvis by urine, as a result of obstruction of the outflow of urine distal to the renal pelvis. It is usually physiological. The objective of this study was to determine the prevalence of maternal hydronephrosis, and correlate it with age, parity and gestational age in normal pregnancy in Bayelsa State, Nigeria.

Methods: This prospective study was conducted at the obstetrics and gynaecology, and radiology departments of the two tertiary hospitals in Bayelsa State, Nigeria, over a six-month period. Sonographic measurements of pelvicalyceal diameters of 400 consecutive normal pregnant women were done, after written informed consent. Data were entered into a pre-designed proforma, and analysed using Statistical Product and Service Solutions (SPSS) version 25.0. Results were presented in frequencies and percentages for categorical variables; mean and standard deviation for continuous variables; Student's t-test to compare sample means; and Chi-square for associations.

Results: Four hundred pregnant women were scanned. Pelvicalyceal dilatation was present in 144 (36\%) women; it affected one kidney in 108 (27\%) women; while in $36(9 \%)$ women, the two kidneys were affected. Renal calculi were present in $16(4 \%)$ women. The right kidney was affected in $12(3 \%)$ women and the left kidney in $4(1 \%)$ women.

Conclusions: The prevalence of hydronephrosis in this study is lower than that from many centres. Pelvicalyceal dilatation was more on the right, and the degree of dilatation increased with increasing gestational age.
\end{abstract}

Keywords: Hydronephrosis, Pregnancy, Pelvicalyceal dilatation, Kidneys, Calculi

\section{INTRODUCTION}

Hydronephrosis is the dilatation of the renal calyces and pelvis by urine, as a result of obstruction of the outflow of urine distal to the renal pelvis. ${ }^{1}$ Hydronephrosis can be physiologic or pathologic; acute or chronic; unilateral or bilateral; secondary to obstruction of the urinary tract or without obstruction. ${ }^{1}$ In pregnancy, hydronephrosis is usually physiological, and occurs due to the compression of the ureters by the pregnant uterus. Physiological dilatation of the ureters due to the smooth muscle relaxing effect of progesterone is also implicated.

Hydronephrosis is usually a common finding in pregnancy, and more common in the right kidney than the left kidney. ${ }^{1-3}$ It is also more common in the primigravida, and usually starts in the second trimester of pregnancy. It resolves about six to twelve weeks post-partum. Sometimes, there can be an obstruction by a renal calculi which may cause or complicate an already existing hydronephrosis. ${ }^{2}$ Pelvicalyceal dilatation can also be 
associated with upper urinary tract infection due to stasis of urine.

The changes seen in the kidneys in hydronephrosis are visualised on ultrasound scan, which is also used to differentiate physiological hydronephrosis from an existing pathological hydronephrosis, like in the presence of a renal calculi. Grading of the degree of hydronephrosis is challenging, as there is presently no consensus on the most appropriate grading system to use among clinicians and radiologists. ${ }^{4}$ The antero-posterior diameter is very dynamic. Factors like respiration, hydration, positioning and bladder filling affect the measurement of anteroposterior diameter. ${ }^{4}$ Due to the different renal pelvic configurations, the measurement of antero-posterior diameter is very variable and misleading. ${ }^{4}$ For the purpose of our study, the grading system by the Society of Foetal Urology (SFU), that was initially developed for use in neonates and infants, but has found use in adults was used. ${ }^{5}$ It is presently the most commonly used grading system. ${ }^{5}$

Most of the pregnant women with hydronephrosis are asymptomatic, and are managed conservatively if discovered incidentally on ultrasound scan. ${ }^{6}$ However, in the presence of urinary tract infection, the patient should be treated with antibiotics. Surgical management should be considered in the presence of obstruction. There is paucity of published local data on hydronephrosis in normal pregnancy, hence, the need for this research. The objective of this study was to determine the prevalence of maternal hydronephrosis, and correlate it with age, parity and gestational age in normal pregnancy in Bayelsa State, Nigeria.

\section{METHODS}

This survey was a prospective, descriptive, cross-sectional study. It was conducted at the Departments of Obstetrics and Gynaecology, and Radiology of the two tertiary hospitals in Bayelsa State, Nigeria, over a six-month period, from July to December 2021. These hospitals are the Niger Delta University Teaching Hospital, Okolobiri. and Federal Medical Centre, Yenagoa. These tertiary health institutions render service, training and research, and are referral centres for hospitals in Bayelsa State and neighbouring Delta and Rivers States.

The sample size for this study was calculated using the formula:

$$
N=\frac{z^{2} p q}{d^{2}}
$$

where, $\mathrm{N}=$ minimum sample size; $\mathrm{z}=$ normal standard deviation set at $95 \%$ confidence limit $=1.96 ; \mathrm{p}=$ prevalence $(63 \%=0.63)$ of hydronephrosis from a previous study. ${ }^{8}$ $\mathrm{d}=$ margin of error $=5 \%=0.05$

\section{Calculation}

$$
N=\frac{(1.96)^{2}(0.63)(0.37)}{(0.05)^{2}}
$$

$\mathrm{N}=358.2$

considering attrition $=10 \%$ of $358.2=35.82$

therefore:

$\mathrm{N}=358.2+35.82=394.02$

'N' was adjusted to 400 .

The dimensions of the renal pelvis and calyx were measured for 400 consecutive normal pregnant women in both tertiary institutions. Pregnant women without any known renal or cardiovascular diseases were included in the study. Women with known medical condition(s) in pregnancy were excluded from the study.

Women who were eligible for the study from the antenatal clinic were counselled, and after obtaining a written informed consent, they were enrolled in the study. These women were referred to the radiology department for routine obstetric ultrasound scan. The age parity, gestational age, and blood pressure of the women, were obtained and documented. To rule out proteinuria and glycosuria prior to ultrasound scan evaluation, urinalysis was done with the use of dipstick.

A real time, grey scale, ultrasound examination was carried out with the use of the 2012 Philips HD11 machine, fitted with a $3.5 \mathrm{MHz}$ curvilinear transducer, with electronic calipers to measure the length, width and thickness of each of the kidneys. Sonography was performed in the semi prone position in other not to put pressure on the pregnant uterus. All patients were required to empty their urinary bladder prior to scanning.

All scans were performed posteriorly through the back. The real time grey scale images were frozen following clear identification of the inferior and superior renal poles in the longitudinal plain. The renal length (L) was taken as the longest distance between the poles using an electronic caliper while the antero-posterior (AP) diameter (thickness) was measured from anterior wall to the posterior wall of the kidney at its mid portion.

The renal width $(\mathrm{W})$ was measured on transverse scan and the maximum transverse diameter was taken at the level of the hilum as the renal width. The unit of measurement was centimeter $(\mathrm{cm})$. Using the formula:

$$
\text { Volume }=\text { Length } \times \text { Width } \times \text { Breadth } \times 0.523
$$

$$
q=1-p(\text { complemantary probablity })
$$


the renal volume was calculated. The pelvicalyceal diameter was measured, and assessment of the degree of pelvicalyceal dilatation was made and documented.

The degree of hydronephrosis was graded with the Society for Foetal Urology (SFU) grading system as follows (Figure 1). ${ }^{5}$

\section{Grade 0}

No dilatation, calyceal walls are apposed to each other.

\section{Grade 1 (mild)}

Dilatation of the renal pelvis without dilatation of the calyces (can also occur in the extrarenal pelvis).

No parenchymal atrophy.

\section{Grade 2 (mild)}

Dilatation of the renal pelvis (mild) and calyces (pelvicalyceal pattern is retained) and no parenchymal atrophy.

\section{Grade 3 (moderate)}

Moderate dilatation of the renal pelvis and calyces; blunting of fornices and flattening of papillae; and mild cortical thinning may be seen.

\section{Grade 4 (severe)}

Gross dilatation of the renal pelvis and calyces, which appear ballooned; loss of borders between the renal pelvis and calyces; and renal atrophy seen as cortical thinning. In this study, grade 0 corresponded to no dilatation; grade 1 and 2 corresponded to mild dilatation; grade 3 corresponded to moderate dilatation; and grade 4 corresponded to severe dilatation. Data were entered into a pre-designed proforma, and were analysed using statistical software (Statistical Product and Service Solutions for windows ${ }^{\circledR}$ version 25, SPSS Inc.; Chicago, USA). Results were presented in frequencies and percentages for categorical variables; mean and standard deviation for continuous variables; Student's t-test used to compare sample means; and Chi-square for associations.

\section{RESULTS}

\section{Demographic characteristics and clinical features}

About a third (30\%) of the pregnant women were aged between 25-29 years, while a quarter $(25 \%)$ were aged between 30 and 34 years. The mean age of the 400 women in the study was 28.7 years with a standard deviation of 6.1 years (Table 1). The median parity was 1 , and it ranged between 0 and 6 . Most (39\%) women were nulliparous, and $56 \%$ were in the second trimester of pregnancy (Table $1)$.

\section{Occurrence and severity of renal calyceal dilatation among pregnant women}

Table 2 shows that pelvicalyceal dilatation was present in 144 (36\%) women; it affected one kidney in 108 (27\%) women; while in 36 (9\%) women, the two kidneys were affected. Renal calculi were present in $16(4 \%)$ women. The right kidney was affected in $12(3 \%)$ women and the left kidney in 4 (1\%) women.

The right kidney was more affected by pelvicalyceal dilatation. Mild, moderate and severe dilatations were observed in the right kidney of $26 \%, 7 \%$ and $11 \%$ of the women respectively, while mild, moderate and severe dilatation in the left kidney was observed in 19\%, 3\% and $2 \%$ of the women respectively (Table 3 ).

\section{Association of pelvicalyceal dilatation with age and renal dimensions}

The occurrence of pelvicalyceal dilatation was highest $(48.6 \%)$ among women in the third trimester of pregnancy and was least (14.3\%) among women in the first trimester, showing a significantly $\left(\chi^{2}=4.78 ; \mathrm{p}=0.030\right)$ increasing trend as pregnancies progressed (Table 4$)$. Table 4 further showed that age and parity were not associated with pelvicalyceal dilatation $(\mathrm{p}>0.05)$.

The Student's t-test that explored the difference between the values of renal parameters among women with and without pelvicalyceal dilatation showed no significant difference $(\mathrm{p}>0.05)$. Renal dimensions were not affected by pelvicalyceal dilatation (Table 5).

Table 1: Demographic and obstetric features.

\begin{tabular}{|lll|}
\hline Characteristics & Frequency N=400 & Percent $(\%)$ \\
\hline Age (years) & & 7.0 \\
\hline$>20$ & $28(7.0)$ & 19.0 \\
\hline $20-24$ & $76(19.0)$ & 30.0 \\
\hline $25-29$ & $120(30.0)$ & 25.0 \\
\hline $30-34$ & $100(25.0)$ & 19.0 \\
\hline$>35$ & $76(19.0)$ & \\
\hline Mean age \pm SD in years & $28.7 \pm 6.1$ & \\
\hline Parity & & \\
\hline
\end{tabular}




\begin{tabular}{|lll|}
\hline Characteristics & Frequency $\mathbf{N}=\mathbf{4 0 0}$ & Percent $(\%)$ \\
\hline Nulliparous & $156(39.0)$ & 39.0 \\
\hline Primiparous & $92(23.0)$ & 23.0 \\
\hline Multiparous & $132(33.0)$ & 33.0 \\
\hline Grand multiparous & $20(5.0)$ & 5.0 \\
\hline Median parity & $1(0-6)$ & $0-6$ \\
\hline Trimester of pregnancy & & 7.0 \\
\hline First trimester & $28(7.0)$ & 56.0 \\
\hline Second trimester & $224(56.0)$ & 37.0 \\
\hline Third trimester & $148(37.0)$ & \\
\hline
\end{tabular}

Table 2: Occurrence of renal pelvicalyceal dilatation and calculi in the women.

\begin{tabular}{|lll|}
\hline Characteristics & Frequency $\mathbf{N}=\mathbf{4 0 0}$ & Percent \\
\hline Calyceal dilatation & \\
\hline No pelvicalyceal dilatation & 256 & 64.0 \\
\hline Pelvicalyceal dilatation present & 144 & 36.0 \\
\hline Number of kidneys affected & & \\
\hline None & 256 & 64.0 \\
\hline 1 kidney & 108 & 27.0 \\
\hline 2 kidneys & 36 & 9.0 \\
\hline Renal calculi & 384 & 96.0 \\
\hline No calculi & 16 & 4.0 \\
\hline Calculi & $\mathrm{N}=16$ & 1.0 \\
\hline The kidneys affected by calculi & 4 & 3.0 \\
\hline Left kidney & 12 & \\
\hline Right kidney & & \\
\hline
\end{tabular}

Table 3: Severity of renal pelvicalyceal dilatation in the right and left kidneys.

\begin{tabular}{|lll|}
\hline Severity & Right kidney $\mathbf{N}=\mathbf{4 0 0}(\%)$ & Left kidney $\mathbf{N}=\mathbf{4 0 0}(\%)$ \\
\hline No dilatation & $224(56.0)$ & $304(76.0)$ \\
\hline Mild dilatation & $104(26.0)$ & $76(19.0)$ \\
\hline Moderate dilatation & $28(7.0)$ & $12(3.0)$ \\
\hline Severe dilatation & $44(11.0)$ & $8(2.0)$
\end{tabular}

Table 4: Relationship between renal pelvicalyceal dilatation and age, parity and gestational age.

\begin{tabular}{|llllll|}
\hline Characteristics & Total & $\begin{array}{l}\text { Calyceal dilatation } \\
\text { Dilated N }(\%)\end{array}$ & Not dilated N $(\%)$ & $\begin{array}{l}\text { Chi } \\
\text { square }\end{array}$ & P value \\
\hline Age (years) & & & & & \\
\hline$>20$ & 28 & $4(14.3)$ & $24(85.7)$ & & 0.573 \\
\hline $20-24$ & 76 & $32(42.1)$ & $44(57.9)$ & & \\
\hline $25-29$ & 120 & $36(30.0)$ & $84(70.0)$ & & \\
\hline $30-34$ & 100 & $44(44.0)$ & $56(56.0)$ & & \\
\hline$>35$ & 76 & $48(63.2)$ & $28(36.8)$ & & \\
\hline Parity & 156 & $52(33.3)$ & $104(66.7)$ & & \\
\hline Nulliparous & 92 & $36(39.1)$ & $56(60.9)$ & & \\
\hline Primiparous & 132 & $48(36.4)$ & $84(63.6)$ & & \\
\hline Multiparous & 20 & $8(40.0)$ & $12(60.0)$ & & \\
\hline Grand multiparous & & & & \\
\hline Trimester of pregnancy & & & & & \\
\hline First trimester & 28 & $4(14.3)$ & $24(85.7)$ & & \\
\hline Second trimester & 224 & $68(30.4)$ & $156(69.6)$ & & \\
\hline Third trimester & 148 & $72(48.6)$ & $76(51.4)$ & & \\
\hline
\end{tabular}

Note: Significant value. 
Table 5: Renal pelvicalyceal dilatation and renal measurements.

\begin{tabular}{|lllllll|} 
Renal parameters & $\begin{array}{l}\text { Right kidney } \\
\text { Dilated } \\
\text { Mean } \pm \text { SD }\end{array}$ & $\begin{array}{l}\text { Not dilated } \\
\text { Mean } \pm \text { SD }\end{array}$ & $\begin{array}{l}\text { t-test } \\
\text { (p value) }\end{array}$ & $\begin{array}{l}\text { Left kidney } \\
\text { Dilated } \\
\text { Mean } \pm \text { SD }\end{array}$ & $\begin{array}{l}\text { Not dilated } \\
\text { Mean } \pm \text { SD }\end{array}$ & $\begin{array}{l}\text { t-test } \\
\text { (p value) }\end{array}$ \\
\hline Renal bipolar length & $11.01 \pm 0.94$ & $10.92 \pm 1.03$ & $0.44(0.663)$ & $11 . .19 \pm 0.92$ & $10.84 \pm 1.03$ & $1.68(0.097)$ \\
\hline $\begin{array}{l}\text { Renal anteroposterior } \\
\text { diameter }\end{array}$ & $4.71 \pm 0.57$ & $4.62 \pm 0.61$ & $0.71(0.482)$ & $4.83 \pm 0.66$ & $4.69 \pm 0.52$ & $1.12(0.264)$ \\
\hline Renal width & $6.65 \pm 0.65$ & $6.38 \pm 0.75$ & $1.82(0.073)$ & $6.49 \pm 0.56$ & $6.26 \pm 0.80$ & $1.48(0.141)$ \\
\hline Renal volume & $181.39 \pm 42.63$ & $170.41 \pm 49.05$ & $1.12(0.264)$ & $184.89 \pm 45.17$ & $167.89 \pm 40.62$ & $1.93(0.057)$ \\
\hline
\end{tabular}

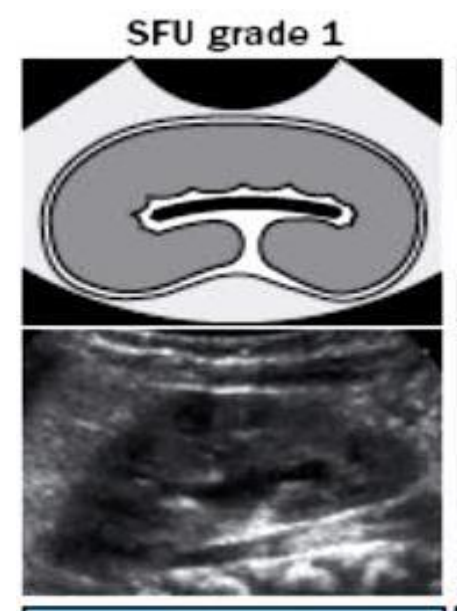

Urine barely splits sinus

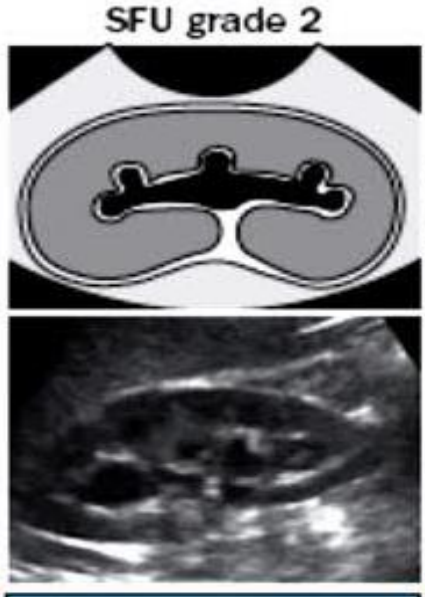

Full pelvis, major calyces dilated
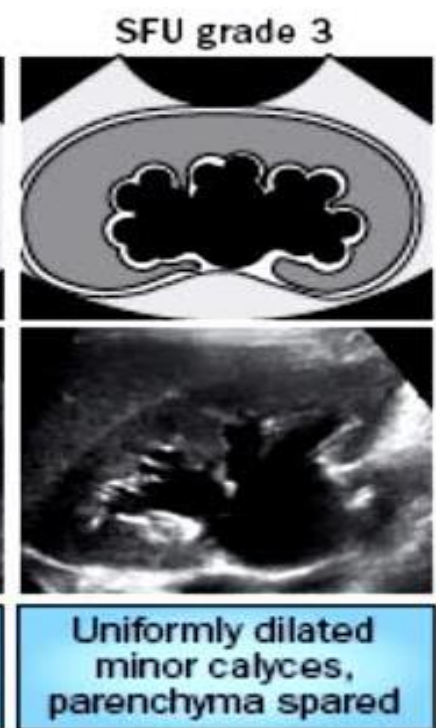

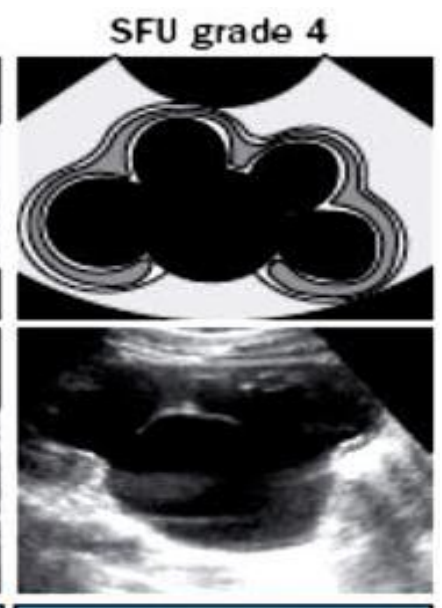

Parenchymal compromise

Figure 1: Society for Foetal Urology (SFU) grading system for hydronephrosis. ${ }^{9}$

\section{DISCUSSION}

In normal pregnancy, physiological dilatation of the urinary collecting system is common, and it spontaneously returns to normal after delivery. This physiological dilatation occurs due to the smooth muscle relaxing effect of progesterone, and the compressive effect of the pregnant uterus on the ureters. Our study revealed that only $36 \%$ of the participants had pelvicalyceal dilatation. This is far lower than the $63-100 \%$ reported by previous studies, but far higher than the $4.1-9 \%$ reported by other authors. ${ }^{1-}$ 3,8,10-16 The reason for this wide variation in incidence rates may be as result of the use of different grading systems which are very subjective in the assessment of hydronephrosis in pregnancy. It may also be due to the differences in the genetic makeups of people that live in the different geographical regions of the world.

In our study, pelvicalyceal dilatation was more on the right. This is keeping with reports from previous studies. ${ }^{1-}$ 3,10-13,15-17 The reason for this may be due to the dextrorotation of the pregnant uterus to the right, compressing the right ureter, and partially sparing the left ureter. The crossing of the right ureter by the right iliac and ovarian vessels in the pelvic brim may also be a predisposing factor to pelvicalyceal dilatation. This research showed that only $4 \%$ of the women that had hydronephrosis also had renal calculi. This is just slightly lower than the $6.1 \%$ reported by Mandal and his colleagues. ${ }^{14}$ Glomerular filtration rate increases in pregnancy. Due to this increase, there is increase in the urinary excretion of uric acid, and consequently, the formation of calcium oxalate stones. Our study revealed that the degree of pelvicalyceal dilatation increased with increasing gestational age. This is in tandem with the reports of previous authors. ${ }^{12,13,16,17}$ The reason for this may be due to the fact that as the gestational age increases, the foetus and the uterus increase in size and weight, and consequently, the compression of the ureters becomes more.

This study showed that age and parity were not associated with calyceal dilatation $(\mathrm{p}>0.05)$. This is however, not in agreement with some previous studies, where women with low parity were more susceptible to developing hydronephrosis. ${ }^{11,18-20}$ This may be due to the fact that the abdominal walls of women with low parity are less lax compared to those of multiparous and grand-multiparous women. The severity of hydronephrosis increases with increasing parity. ${ }^{11}$ The strength of this research was that it was a two-centre prospective study, where women with normal pregnancies and asymptomatic for hydronephrosis were recruited. This removed confounding variables, like renal pathologies and medical conditions in pregnancy, 
which may have affected renal assessment and measurements.

This study was limited by the fact that it was hospitalbased. Therefore, the findings cannot be used to draw general conclusions in the population of pregnant women. A multi-centre randomised control trial with a larger sample size will be more representative.

\section{CONCLUSION}

The proportion of pregnant women in this study with hydronephrosis is lower than those in the reports from many of centres around the globe. This study established that pelvicalyceal dilatation was more on the right, and that the degree of pelvicalyceal dilatation increased with increasing gestational age, but not affected by age and parity of the women.

\section{ACKNOWLEDGMENTS}

We appreciate all the patients and staff of the health institutions for all their roles in making this research possible. Dr. Adesina, Adedotun Daniel is also appreciated for analysing the data for this research.

Funding: No funding sources

Conflict of interest: None declared

Ethical approval: The study was approved by the Institutional Ethics Committee

\section{REFERENCES}

1. Medscape. Hydronephrosis and Hydroureter: Pathophysiology, Epidemiology, 2022. Available at: https://emedicine.medscape.com/article. Accessed on 22 January 2022.

2. Radiopaedia. Maternal hydronephrosis in pregnancy, 2022. Available at: https://radiopaedia.org/ articles/maternalhydronephrosis-in-pregnancy. Accessed on 22 January 2022.

3. Rasmussen PE, Nielsen FR. Hydronephrosis during pregnancy: a literature survey. Eur J Obstet Gynecol Reprod Biol. 1988;27(3):249-59.

4. Onen A. Grading of Hydronephrosis: An Ongoing Challenge. Front Pediatr. 2020;8:458.

5. Namdev R. Hydronephrosis grading (SFU system), 2021. Available at: https://radiopaedia.org/ articles/hydronephrosisgrading-sfu-system. Accessed on 22 January 2022.

6. Fainaru O, Almog B, Gamzu R, Lessing JB, Kupferminc $\mathrm{M}$. The management of symptomatic hydronephrosis in pregnancy. BJOG. 2002;109(12):1385-7.
7. Araoye MO. Subjects Selection. In: Research Methodology with statistics for Health and Social sciences. 1st ed. Ilorin: Nathadex Publishers; 2003: 115-129.

8. Grosjean J, Cannie M, Meyer JM. Physiological hydronephrosis in pregnancy: Occurrence and possible causes. An MRI study. Prog Urol. 2017;27(12):603-8.

9. Fernbach SK, Maizels M, Conway JJ. Ultrasound grading of hydronephrosis: introduction to the system used by the Society for Fetal Urology. Pediatr Radiol. 1993;23(6):478-80.

10. Oyinloye OI, Okoyomo OO. Evaluation of hydronephrosis, during pregnancy in Nigerian women. Niger J Clin Pract. 2010;13(1):51-4.

11. Ciciu E, Cornea AM, Petcu LC, Tuţă LA. Early diagnosis and management of maternal ureterohydronephrosis during pregnancy. Exp Ther Med. 2022;23(1):27.

12. Peake SL, Roxburgh HB, Langlois SL. Ultrasonic assessment of hydronephrosis of pregnancy. Radiology. 1983;146(1):167-70.

13. Cietak KA, Newton JR. Serial qualitative maternal nephrosonography in pregnancy. $\mathrm{Br} \mathrm{J}$ Radiol. 1985;58(689):399-404.

14. Mandal D, Saha MM, Pal DK. Urological disorders and pregnancy: An overall experience. Urol Ann. 2017;9(1):32-6.

15. The $S$, Chan LW. Pelvicalyceal dilatation in maternal kidneys during normal pregnancy - an uncommon finding? J Urol. 2008;179(4S):726-6.

16. Wadasinghe SU, Metcalf L, Metcalf P, Perry D. Maternal Physiologic Renal Pelvis Dilatation in Pregnancy: Sonographic Reference Data. J Ultrasound Med Off J Am Inst Ultrasound Med. 2016;35(12):2659-64.

17. Bayraktar Z, Kahraman ŞT, Alaç ES, Yengel İ, Kalkan D. Maternal hydronephrosis in pregnant women without ureteral stones and characteristics of symptomatic cases who need treatment: A singlecenter prospective study with 1026 pregnant women. Arch Ital Urol Androl Organo Uff Soc Ital Ecogr Urol E Nefrol. 2021;93(1):35-41.

18. Puskar D, Balagović I, Filipović A, Knezović N, Kopjar M, Huis M, et al. Symptomatic physiologic hydronephrosis in pregnancy: incidence, complications and treatment. Eur Urol. 2001;39(3):260-3.

19. Eckford SD, Gingell JC. Ureteric obstruction in pregnancy--diagnosis and management. Br J Obstet Gynaecol. 1991;98(11):1137-40.

20. Zwergel T, Lindenmeir T, Wullich B. Management of acute hydronephrosis in pregnancy by ureteral stenting. Eur Urol. 1996;29(3):292-7.

Cite this article as: Oriji PC, Kiridi EK, Abasi IJ. Maternal hydronephrosis in normal pregnancy in Bayelsa state, South-South Nigeria. Int J Reprod Contracept Obstet Gynecol 2022;11:664-9. 